\title{
DAKWAH AKOMODATIF: Solusi Dakwah Aplikatif Fungsional Pada Masyarakat Multikultural
}

\author{
Fahrurrozi \\ Fakultas Dakwah Dan Komunikasi UIN Mataram \\ e-mail: roziqi_iain@yahoo.co.id
}

\begin{abstract}
Da'wah in the reality of the society Indonesia multiple and plural gives a very wide space by The 1945 Constitution Article 29 paragraph 2 ensures the freedom of every citizen to embrace religion and trust and worship in accordance with his religion and his belief that. However, in practice, activities Da'wah in Indonesia still faces obstacles. Propagation is done by an individual or institutional basis, it still showed the selfishness and personal groups. With on behalf of truth and religion, their assault against another group or congregation. Problem calling other important enough is concerned the difference understand that often makes social relations with the dominant religion is compromised, even in certain levels could cause social insecurity. This article gives the concept of charity donations that is considered relevant to the context of the present model is the Da'wah accommodating, the focus was more on point accommodation to reality empirical sociological even theological society that multicultural. With this approach could be tested that Islam Rahman li alAlamein, and harmonization of the people in the midst of global challenges and technologies.
\end{abstract}

\section{Key Words:}

Accommodating, Reality, Global, Multicultural Da'wah 


\begin{abstract}
Abstrak
Dalam realita masyarakat Indonesia yang plural dan multikultural dakwah memberikan ruang yang luas oleh undang undang 1945 pasal 29 ayat 2 yang menjamin kebebasan setiap warga negara untuk memeluk agama dan kepercayaan dan beribadah menurut agama dan kepercayaannya. Namun, praktiknya aktifitas-aktifitas da'wah di Indonesia masih menghadapi tantangan. Penyebarannya msih dilakukan oleh individu atau berbasis institusional. Masih menunjukkkan keegoisan dan grup pribadi. Atas nama kebenaran dan agama, mereka menyerang kelompok atau jema'ah yang lain. Soal pemanggilan yang cukup penting lainnya adalah memperhatikan perbedaan pengertian yang kerap membuat hubungan sosial dengan agama dominan dikompromikan, bahkan pada tingkat tertentu bisa menimbulkan keresahan sosial. Artikel ini memberikan konsep sumbangan amal yang dianggap relevan dengan konteks model saat ini yaitu akad Dakwah, fokusnya lebih pada titik akomodasi realitas sosiologis bahkan sosiologis bahkan masyarakat teologis yang multikultural. Dengan pendekatan ini dapat diuji bahwa Islam Rahman li al-Alamein, dan harmonisasi masyarakat di tengah tantangan dan teknologi global.
\end{abstract}

\title{
Kata Kunci:
}

Akomodatif, Realitas, Global, Dakwah Multikultural 


\section{A. Pendahuluan}

Dakwah Islam merupakan suatu gerakan perubahan kondisi masyarakat ke arah yang lebih baik berdasarkan tolok ukur ajaran Islam. Perubahan-perubahan tersebut tidak hanya berkaitan dengan kondisi lahiriah, tetapi juga pola pikir masyarakat, terutama dalam menyikapi realitas keberagamannya. Namun, ketika berbicara tentang dakwah Islam di tengah masyarakat multicultural, tantangan secara globalnya dapat dideskripsikan menjadi tiga dimensi, yaitu:

Dimensi pertama, tantangan global-postmodernisme yang antara lain bercirikan: (1) timbulnya pemberontakan secara kritis terhadap modernitas; memudarnya kepercayaan pada agama yang bersifat transendental (meta narasi); dan semakin diterimanya pandangan pluralisme-relativisme kebenaran; (2) meledaknya industri media massa, sehingga ia bagaikan perpanjangan dari sistem indra, organ, dan saraf, yang pada gilirannya membuat dunia menjadi terasa kecil. Lebih dari itu, kekuatan media massa telah menjelma bagaikan "agama" dan "tuhan" sekuler, dalam arti bahwa perilaku orang tidak lagi ditentukan oleh agama-agama tradisional, tetapi tanpa disadari telah diatur oleh media massa; (3) munculnya radikalisme etnis dan keagamaan. Fenomena ini muncul diduga sebagai reaksi atau alternatif ketika orang semakin ragu terhadap kebenaran sains, teknologi dan filsafat yang dinilai gagal memenuhi janjinya untuk membebaskan manusia dan kemanusiaan. ${ }^{1}$

Dimensi kedua, adalah ketertinggalan dunia Islam. Bahwa sejak enam abad terakhir praktis kepemimpinan dunia dipegang oleh Barat, setelah sebelumnya dunia Islam. Dunia Islam jauh ketinggalan dalam mengembangkan peradaban sains dan teknologi dan kreasi-kreasi

'Untuk penjelasan lebih lanjut dapat dilihat pada Komaruddin Hidayat, "Agama Dan Postmodernisme", dalam Tragedi Raja Mida: Moralitas Agama dan Krisis Modernisme, (Jakarta: Paramadina, 1998), 152-3; Juga Akbar S. Ahmed, "Postomdernism and Islam: Predicament and Promise", teri. M. Sirozi dengan judul Posmodernisme: Tantangan dan Harapan bagi Islam, (Bandung: Mizan, 1993), 25-42. 
lain. Islam sebagai paradigma syari'at dan teologi memang kelihatan masih kokoh (untuk tidak menyatakan jumud atau beku), tetapi Islam sebagai paradigma peradaban berada di luar panggung permainan, dan cenderung sebagai penonton yang "cemburu". ${ }^{2}$

Dimensi ketiga, ini yang paling langsung dan paling mendesak, adalah kondisi internal Lembaga Dakwah dan Institusi pendidikannyadidirikan sesuai dengan tuntutan zaman atau kondisi ketika lembaga tersebut didirikan, yang tentunya dengan paradigma yang tidak lagi relevan dengan era global dewasa ini. Ketidakrelevan-an tersebut terlihat dari dua sisi, (1) paradigmanya sangat sektoral, dan (2) visi serta misi yang dimilikinya sangat terbatas, dan karenanya hanya mungkin memenuhi satu sektor tertentu saja dari kebutuhan umat Islam Indonesia modern, tetapi tidak mungkin diharapkan untuk menghasilkan manusia-manusia yang kompetitif yang dapat unggul dalam persaingan masyarakat global (knowledge society) pada abad 21 yang akan datang. ${ }^{3}$

\section{B. Dakwah Akomodatif Dalam Tilikan Teori Dakwah}

Perspektif dalam bidang ilmu pengetahuan sering juga diistilahkan dengan paradigma atau mazhab pemikiran (school of thought) atau teori. Istilah-istilah lain yang sering diidentikkan dengan perspektif adalah model, pendekatan, strategi intelektual, kerangka konseptual, kerangka pemikiran, dan pandangan dunia (world view). B Aubrey Fisher $^{4}$ seorang ilmuan komunikasi menggunakan istilah perspektif alih-alih teori karena ia tidak yakin apa yang disebut teori dan karena bidang komunikasi belum mengembangkan teori-teori yang memperoleh parsimony (hemat universal) sebagaimana ilmu-ilmu alam (natural science). Dalam konteks ini argument Fisher dapat dipahami

${ }^{2}$ Hidayat, Tragedi ..., 154.

${ }^{3}$ A.R. Tilaar, Beberapa ..., 208-209.

${ }^{4}$ B. Aubrey Fisher, 1986. Teori-teori Komunikasi, teri. Soejono Trimo, (Bandung: Remaja Rosda Karya), 86. 
karena membicarakan teori pada dasarnya membicarakan perspektif yang melatarbelakanginya.

Sementara itu menurut Thomas Kuhn ${ }^{5}$ paradigma adalah suatu cara pandang untuk memahami kompleksitas dunia nyata. Sebagaimana dikatakan Patton ${ }^{6}$ paradigma tertanam kuat dalam sosialisasi para penganut dan praktisinya: paradigma menunjukkan pada mereka apa yang penting, abash dan masuk akal. Paradigma juga bersifat normative menunjukan pada praktisinya apa yang harus dilakukan tanpa perlu mempertimbangkan eksistensial atau epistemologis yang panjang. Akan tetapi menurut Patton aspek paradigma inilah yang sekaligus merupakan kekuatan dan kelemahannya-kekuatannya adalah hal itu memungkinkan tindakan, kelemahannya adalah alasan untuk melakukan tindakan tersebut tersembunyi dalam asumsi-asumsi paradigma yang tidak dipersoalkan.

Salah satu makna paradigma, sebagaimana dikemukan Anderson, adalah 'ideologi dan praktik suatu komunitas ilmuan yang menganut pandangan yang sama atas suatu realitas. Memiliki seperangkat kriteria yang sama untuk menilai aktivitas, dan menggunakan metode serupa. Dalam kaitan ini ada dua kerangka besar paradigma, yaitu paradigma structural dan paradigma fungsional. Kedua paradigma ini sering dipertukarkan, namun paradigma yang pertama jangkauannya lebih luas dibanding yang kedua sebab mencakup pendekatan marxis (Marxian) untuk membedakan keduanya sering digunakan istilah paradigma structural consensus (yang menekankan pentingnya sosialisasi) dan paradigma strktural konflik. ${ }^{7}$ Namun bila orang menggunakan istilah 'paradigma structural' lazimnya istilah tersebut merujuk pada 'paradigma structural fungsional' dua paradigma lain yang maknanya

${ }^{5}$ Dennis Brissett dan Charles Edgley (ed), Life as Theater (New York: Aldine de Gruyter, 1990), 34.

'Patton, Qualitative ...., 37.

7Philips Jones, Theory and Method in Sociology: A Guide for The Beginner (Slough: Univercity Tutorial Press, 1985), 5-15. 
identik adalah paradigma interpretatif dan paradigma fenomenologis. Karenanya, kedua istilah tersebut dalam penggunaannya sering dipertukarkan.

Dalam kehidupan sehari-hari manusia membutuhkan interaksi antara satu dengan yang lain. ${ }^{8}$ Alat interaksi itu secara akumulatif lazim disebut'komunikasi', yaitu hubungan ketergantungan (interdependensi) antarmanusia baik secara individu maupun secara kelompok. Karena itu disadari atau tidak, komunikasi merupakan bagian penting (urgent) dari kehidupan manusia. Urgensitas komunikasi ${ }^{9}$ pada satu sisi bahkan menjelma menjadi prasarat tersendiri dari keberadaan manusia sebagai makhluk sosial. Sementara pada sisi lain, para pakar berkeyakinan bahwa sesungguhnya manusia telah berkomunikasi dengan lingkungannya semenjak ia dilahirkan. Gerak dan tangis pertama tatkala manusia menapak fase kelahiran sesungguhnya merupakan pertanda bahwa manusia telah mulai dapat berkomunikasi. Ketika manusia telah dapat memfungsikan panca inderanya secara sadar, saat itu pula membutuhkan perhatian dari lingkungan dan manusia lain disekitarnya. Bahkan tak jarang, untuk mendapatkannya, manusia mempergunakan berbagai cara.

Menengok salah satu fungsi komunikasi adalah sebagai komunikasi sosial, yang penulis istilahkan dengan "dakwah akomodatif" setidaknya mengisyaratkan bahwa komunikasi itu penting untuk membangun

\footnotetext{
${ }^{8}$ Tommy, Suprapto, Pengantar Teori Komunikasi (Jogjakarta: Media Presindo, 2006), 1.

'Dalam tulisannya yang beriudul; "Professional Communication in Asia/Pacific Organisations: A Comparative Study" yang dipresentasikan pada Simposium Intercultural Communication di Goteborg, Sweden 26-28 November 1998 Cal W. Downs menunjukkan pentingnya komunikasi dengan mengutip pernyataan Ticehurst and RossSmith yang mengatakan; "Professional communication as intentional communication that has the objective of achieving strategic goals within organisational or professional contexts (1998:3). Dia melanjutkan "The development and maintenance of the linkage between communication and strategic goals of an organisation is the responsibility of the professional communicator. Linking professional communication with strategy is crucial to the way we think about professional communication, and the way we practice it. Journal of Intercultural Communication, ISSN 1404-1634, issue 14, Juni 2010. Editor: Prof. Jens Allwood, URL: http://www.immi.se/intercultural/
} 
konsep diri, aktualisasi diri, untuk kelangsungan hidup, untuk memperoleh kebahagiaan, terhindar dari tekanan dan ketegangan antara lain lewat dakwah atau komunikasi yang bersifat menghibur, dan memupuk hubungan dengan orang lain. Melalui dakwah atau komunikasi kita dapat bekerja sama dengan anggota masyarakat (keluarga, kelompok belajar, perguruan tinggi, RT, RW, desa, kota dan negara secara keseluruhan) untuk mencapai tujuan bersama. Orang yang tidak pernah berkomunikasi dengan manusia, bisa dipastikan akan "tersesat", karena ia tidak berkesempatan menata dirinya dalam suatu lingkungan sosial. Komunikasilah yang memungkinkan individu membangun suatu kerangka rujukan dan menggunakanya sebagai panduan untuk menafsirkan situasi apapun yang ia hadapi.

Tidak ada Islam tanpa ilmu pengetahuan, karena Islam lahir dan dikembangkan dalam wadah ilmu pengetahuan sebagai alat dan medianya. Oleh karena itu sejarah kelahiran dan perkembangan ilmu pengetahuan adalah sejarah Islam itu sendiri, begitu pula sebaliknya sejarah Islam adalah sejarah ilmu pengetahuan dalam Islam. Paralelitas makna sejarah yang demikian itu tidak serta merta memunculkan simpulan bahwa eksistensi ilmu pengetahuan tercerap dalam Islam ataupun sebaliknya Islam menjadi subordinasi dari ilmu pengetahuan. Paralelitas makna sejarah di atas menunjukkan bahwa Islam tidak anti pengetahuan dan sebaliknya bahwa ilmu pengetahuan tidak anti Islam. Islam lahir dalam semangat keilmuan. Semangat keilmuan adalah semangat keterbukaan, semangat kritik, dan semangat untuk selalu menuju kepada kebaikan tertinggi, dan semangat untuk selalu dinamis. Itulah makna spirit dari suatu hadits yang menyatakan al-dín huwa al-aql lí dína li man lí aqla lahí. Pewacanaan Islam seiring dengan semangat penggunaan aql yang selalu berdialektik dengan naql, begitu pula sebaliknya. Sebagai contoh, secara teologis, wahyu pertama yang diturunkan kepada Nabi Muhammad Saw. adalah kata iqra', namun secara bersamaan kata ini juga menunjukkan peran logos-nya sebagai suatu kata-kata yang sarat dengan konsep 'aqliyyah. 
Semangat yang demikian itu-lah yang perlu terus dipahamai lebih dalam dan tentu perlu terus dipelihara dengan suatu keyakinan bahwa Islam perlu terus diwacanakan. Namun demikian perlu juga disadari bahwa mewacanakan agama selalu bersentuhan dengan realitas suatu masyarakat. Kondisi demikian itu mengakibatkan lahirnya wacanawacana keagamaan yang tidak lepas dari sisi sosialitas manusia. Dapat dikatakan bahwa perkembangan gagasan suatu keagamaan tidak dapat dilepaskan dari perkembangan gagasan atas wacana itu sendiri.

Dakwah atau komunikasi tidak saja berkutat pada persoalan pertukaran berita dan pesan, akan tetapi juga melingkupi kegiatan individu dan kelompok terkait dengan tukar menukar data, fakta dan ide. Bila dilihat dari makna ini, ada beberapa fungsi yang melekat dalam proses dakwah yang komunikatif:

1. Informasi, pengumpulan, penyimpanan, pemrosesan, penyebaran berita, data, gambar, fakta, pesan, opini, dan komentar yang dibutuhkan agar dapat dimengerti dan beraksi secara jelas terhadap kondisi lingkungan dan orang lain agar dapat mengambil keputusan yang tepat.

2. Sosialisasi (pemasyarakatan), penyedian sumber ilmu pengetahuan yang memungkinkan orang bersikap dan bertindak sebagai anggota masyarakat yang efektif sehingga ia sadar akan fungsi sosialnya dan dapat aktif di dalam masyarakat

3. Motivasi, menjelaskan tujuan setiap masyarakat jangka pendek maupun jangka panjang, mendorong orang untuk menentukan pilihan dan keinginannya, mendorong kegiatan individu dan kelompok berdasarkan tujuan bersama yang akan dikejar.

4. Perdebatan dan diskusi, menyediakan dan saling menukar faktayang diperlukan untuk memungkinkan persetujuan atau menyelesaikan perbedaan pendapat mengenai masalah publik, menyediakan bukti-bukti relevan yang diperlukan untuk kepentingan umum 
agar masyarakat lebih melibatkan diri dengan masalah yang menyangkut kepentingan bersama.

5. Pendidikan, pengalihan ilmu pengetahuan dapat mendorong perkembangan intelektual, pembentukan watak, serta membentuk keterampilan dan kemahiran yang diperlukan pada semua bidang kehidupan.

6. Memajukan kehidupan, menyebarkan hasil kebudayaan dan seni dengan maksud melestarikan warisan masa lalu, mengembangkan kebudayaan dengan memperluas horizon seseorang serta membangun imajinasi dan mendorong kreativitas dan kebutuhan estetiknya.

7. hiburan, penyebarluasan sinyal, simbol, suara, dan imaji dari drama, tari, kesenian, kesusastraan, musik, olahraga, kesenangan, kelompok, dan individu.

8. Integrasi menyediakan bagi bangsa, kelompok, dan individu kesempatan untuk memperoleh berbagai pesan yang mereka perlukan agar mereka dapat saling kenal dan mengerti serta menghargai kondisi pandangan dan keinginan orang lain.

Dalam konteks tersebut, dakwah akomodatif sangat cocok untuk menjadi pegangan bagi para aktivis sosial, politikus, da'i, muballigh, dan ummat Islam secara luas. Dakwah Akomodatif, sebuah terminologi yang ingin mengintegrasikan antara dua istilah yang berbeda dalam paradigma keilmuan, tapi sesungguhnya sama dari sisi esensi terminologi tersebut.

\section{Penerapan Dakwah Akomodatif dalam Masyarakat Multikultural}

Pendekatan dakwah merupakan titik tolak atau sudut pandang kita terhadap dakwah akomodatif. Pada umumnya, penentuan 
pendekatan dakwah didasarkan pada mitra dakwah dan suasana yang melingkupinya. Dalam bahasa lain, pendekatan dakwah harus tertumpu pada pandangan human oriented, dengan menempatkan pandangan yang mulia atas diri manusia sebagai mitra dakwah. Pendekatan terhadap mitra dakwah lainnya yang bisa digunakan adalah pendekatan sosial kemasyarakatan. Pendekatan ini meliputi pendekatan sosial politik, pendekatan sosial budaya, dan pendekatan sosial ekonomi. Pendekatan dakwah di atas bisa disederhanakan menjadi dua pendekatan, yakni pendekatan stuktural dan pendekatan kultural. 10

Pendekatan-pendekatan tersebut kemudian dapat diakomodir dalam segala dimensi multikultural masyarakat, sehingga masyarakat merasa diayomi dan diakomodasi segala keperluan hajat hidupnya dalam beragama, berbangsa dan bernegara. Inilah esensi dari dakwah akomodatif di tengah multikulturalisme masyarakat. Di mana multikulturalisme dalam agama maupun budaya merupakan keniscayaan yang tidak bisa dibantah. Orang yang mengajak agar melestarikan lingkungannya, mencintai dan menyayangi sesama manusia, saling menghargai dan menghormati, kompetisi sehat dan nilai-nilai kemanusiaan lainnya ternyata bukan hanya monopoli khutbah Sang Pastor di gereja-gereja, nasehat-nasehat mubaligh di podium, para politisi dalam kampanye pemilu atau sikap biksu dan pendeta bijak pada keyakinan dan ajaran-ajaran agama yang berbeda.

Sikap saling membela dalam mempertahankan budaya dan tradisi suatu masyarakat tidak hanya monopoli kaum primitif yang hidup di hutan nan jauh dari keramaian kota seperti suku-suku di Papua dan Kalimantan, tetapi hampir setiap masyarakat menyatu dengan budayanya berhak untuk melestarikannya. Apalagi di era teknologi informasi sekarang, batas-batas budaya, baik secara sosiologis

\footnotetext{
${ }^{10} \mathrm{Aziz}, 1 / m u \ldots, 216$.
} 
maupun geografi sudah sulit untuk dibatasi dan memudahkan untuk berkomunikasi baik secara langsung maupun tidak langsung. Fakta dan kenyataan ini jelas dapat menimbulkan situasi dan suasana tidak menentu bahkan membingungkan bagi sebagian orang, terutama mengandalkan mental interaksi hidupnya pada tradisi hegemoni mayoritas. Konflik kepribadian (personality conflict), konflik individu maupun konflik kelompok dengan latar belakang budaya dan kepentingan yang berbeda-beda terjadi tak terelakkan.

Salah satu jalan untuk menyikapinya atas kenyataan pluralitas ini adalah dengan cara dan sikap mengakui kenyataan tersebut. Kemudian saling mengenal dan bekerjasama dalam memelihara kehidupannya. ${ }^{11}$ Pengakuan terhadap keragaman beragama misalnya, tidak bisa dilaksanakan apabila dalam diri seseorang masih ada perasaan curiga dan prasangka buta yang saling menyalahkan bahkan mencaci agama dan kepercayaan yang ada di luar dirinya. Meskipun setiap agama mempunyai landasan doktriner untuk menyebarkan ajarannya, penyebaran tersebut tetap harus dilakukan dalam suasana saling menghormati kepercayaan agama orang lain. Kasus perkasus tragedi kemanusiaan atas nama agama sudah banyak kita saksikan sebagai bukti bahwa keragaman perbedaan adalah keniscayaan yang harus diakui keberadaannya. Bahkan suatu proyek pembangunan yang dilaksanakan pemerintah sering berakhir dengan benturan antaraparat dan warga hanya karena proyek pembangunan tersebut menyinggung dan mengganggu kebiasaan dan adat-istiadat dalam kelangsungan hidup masyarakat setempat.

Begitu juga dengan dakwah, tidak akan jauh mengalami nasib yang sama apabila pelaksanaan dakwah tersebut tidak memperhatikan dan mengindahkan nilai-nilai budaya termasuk tradisi beragama yang dianut masyarakat. Dakwah tersebut akan ditolak dan segera

"Deddy Mulyana, Komunikasi Efektif, Suatu Pendekatan Lintas Budaya (Bandung: Remaja Rosdakarya, 2004), 91. 
ditinggalkan umat. Padahal, selain untuk diri sendiri, dakwah dilakukan untuk membimbing umat. Aktivitas dakwah pada era sekarang dituntut melakukan upaya-upaya dan pendekatanpendekatan dakwah yang lebih bisa mengayomi dan mempertimbangkan budayabudaya masyarakat tertentu yang berpijak pada nilai-nilai universal kemanusiaan. Dakwah merupakan suatu proses, maka layaknya suatu proses mesti dilakukan dengan cara-cara dan strategi yang lebih terencana, konseptual dan terus-menerus (continue) seraya terus meningkatkan pendekatan-pendekatan yang lebih ramah tanpa mengubah maksud dan tujuan dakwah.

Rekontruksistrategis-konseptual dan reorientasi tujuan dakwah mesti dilakukan, karena dakwah Islam umumnya masih diyakini berasas pada al-Qur'an, maka upaya-upaya rekontruksi, reinterpretasi pemahaman atas teks-teks al-Qur'an mesti dilakukan guna menghindari jurang perbedaan yang terlalu jauh antara pemahaman-pemahaman atas makna dan praktek yang seharusnya (das sein) dipahami da'i dengan praktek-praktek penganut agama (das sollen) yang tidak lepas dari pengaruh-pengaruh budaya masyarakat. Tanpa upaya-upaya sinergi dan komprehensif ini, seperti pendekatan yang terlalu tekstual dan leterlek terhadap pemahaman teks-teks kitab suci akan terasa jauh panggang dari api.

Model pendekatan dakwah yang terlalu tekstual, bukannya mempermudah menyampaikan pesan-pesan dakwah, bahkan akan kembali ke belakang (set back), kalau bukan akan bertabrakan dan kontra produktif dengan arus dinamisnya budaya masyarakat yang cenderung materialistis dan hedonis seperti terjadi pada masa sekarang. Nilai-nilai universal dalam al-Qur'an, jika meminjam rekonstruksi 
teori-teori yang dibangun para pemikir Muslim kontemporer dalam memahami teks al-Qur'an, seperti Hassan Hanafi, Mohammad Arkoun, Muhammad Sahrur dan Nasr Hamid Zaid maka sketsa nilai-nilai alQur'an universal itu terdapat pada kurun periode Mekah. Mungkin suasananya lebih tepat apabila tema-tema universal itu mengemuka disampaikan para da'i antar-budaya.

Multikulturalisme adalah paradigma yang menganggap adanya kesetaraan antar ekspresi budaya yang plural. Multikulturalisme mengusung kesadaran sosial bahwa di dalam ranah kehidupan masyarakat terdapat keragaman budaya. ${ }^{12}$ Kesadaran tersebut berdimensi etis yang menuntut tanggungiawab yang terarah pada ortopraksis (tindakan baik dan benar), yang selanjutnya terwujud ke dalam berbagai bentuk penghargaan, penghormatan, perhatian, kasih sayang, cinta, dan pengakuan akan eksistensi terhadap sesama. Pengertian multikulturalisme yang diberikan para ahli sangat beragam. Multikulturalisme pada dasarnya merupakan pandangan dunia (worldview), yang selanjutnya diterjemahkan ke dalam berbagai kebijakan kebudayaan, yang menekankan penerimaan terhadap adanya realitas keragaman, pluralitas, dan multikultural yang terdapat dalam kehidupan masyarakat. ${ }^{13}$ Multikulturalisme dapat juga dipahami sebagai pandangan dunia (worldview) yang kemudian diwujudkan dalam "politics of recognition". ${ }^{14}$ Karena pengertian multikulturalisme sangat beragam, maka konsep dan prakteknya cenderung berkembang, maka Bikhu Parekh membedakan multikulturalisme ke dalam lima macam, yaitu:

Multikulturalisme isolasionis, mengacu kepada kehidupan masyarakat di mana berbagai kelompok kultural yang menjalankan kehidupannya

\footnotetext{
${ }^{12}$ Parsudi Suparlan, Menuju Masyarakat Indonesia Yang Multikultural, (Jakarta: Gramedia, 2002), 13.

${ }^{13}$ Thomas La Belle \& Christopher Ward, Multiculturalism and Education, (Albany: SUNY Press, 1994), 53.

${ }^{14}$ Charles Tayler, Multiculturalism: Examining The Politics of Recognition, (Princeton: Princeton Univercity Press, 1994), 35.
} 
secara otonom dan terlibat adalah masyarakat yang ada pada sistem "millet" di Turki Usmani atau masyarakat Amish di Amerika Serikat. Kelompok ini menerima keragaman, tetapi pada saat yang sama berusaha mempertahankan budaya mereka secara terpisah dari masyarakat lain umumnya.

MultikulturalismeAkomodatif. Dalammasyarakatyang plural, mereka yang memiliki kultur dominan membuat penyesuaian-penyesuaian dan akomodasi-akomodasi tertentu bagi kebutuhan kultural kaum minoritas. Masyarakat multikultural akomodatif merumuskan dan menerapkan undang-undang, hukum dan ketentuan-ketentuan yang sensitif secara kultural, dan memberikan kebebasan kepada kaum minoritas untuk mempertahankan dan mengembangkan kebudayaan mereka, sebaliknya kaum minoritas tidak menantang kultur dominan. Multikulturalisme akomodatif ini dapat ditemukan di Inggris, Prancis, dan beberapa negara Eropa lain.

Multikulturalisme otonomis, yakni masyarakat plural di mana kelompok-kelompok kultural utama berusaha mewujudkan kesetaraan (equality) dengan budaya dominan dan menginginkan kehidupan otonom dalam kerangka politik yang secara kolektif bisa diterima. Perhatian pokok kelompok-kelompok kultural ini adalah untuk mempertahankan cara hidup mereka, yang memiliki hak yang sama dengan kelompok dominan, mereka menantang kelompok kultural dominan dan berusaha menciptakan suatu masyarakat di mana semua kelompok bisa eksis sebagai mitra sejajar. Jenis multikulturalisme didukung misalnya oleh kelompok Quebecois di Canada, dan kelompok-kelompok Muslim imigran di Eropa, yang menuntut untuk bisa menerapkan syari `ah, mendidik anak-anak mereka pada sekolah Islam, dan sebagainya. ${ }^{15}$

${ }^{15}$ Bikhu Parekh, National Culture and Multiculturalism (New Delhi: Amar Prahasan, 1997) 123-126. 
Multikulturalisme kritikal atau interaktif, yakni masyarakat plural di mana kelompokkelompok kultural tidak terlalu concern dengan kehidupan kultural otonom, tetapi lebih menuntut penciptaan kultur kolektif yang mencerminkan dan menegaskan perspektifperspektif distingtif mereka. Kelompok budaya dominan tentu saja cenderung menolak tuntutan ini, dan bahkan berusaha secara paksa untuk menerapkan budaya dominan mereka dengan mengorbankan budaya kelompok-kelompok minoritas. Karena itulah kelompok-kelompok minoritas menentang kelompok kultur dominan, baik secara intelektual maupun politis, dengan tujuan menciptakan iklim yang kondusif bagi penciptaan secara bersamasama sebuah kultur kolektif baru yang egaliter secara genuine. Jenis multikulturalisme seperti ini, sebagai contoh, diperjuangkan masyarakat kulit Hitam di Amerika Serikat, Inggris dan lain-lain.

Multikulturalisme kosmopolitan, yang berusaha menghapuskan batasbatas kultural sama sekali untuk menciptakan sebuah masyarakat di mana setiap individu tidak lagi terikat dan committed kepada budaya tertentu dan, sebaliknya, secara bebas terlibat dalam eksperimen-eksperimen interkultural dan sekaligus mengembangkan kehidupan kultural masingmasing. ${ }^{16}$ Dalam konteks dakwah yang berhadapan lansung dengan masyarakat yang sangat mejemuk dan multikultural, maka sangat relevan diterapkan teori multikulturalisme akomodatif sebagai solusi yang dipandang relevan dan sesuai dengan tuntunan zaman dan situasi kondisi.

\section{Penutup}

Dakwah akomodatif sesungguhnya dakwah dalam konteks memberikan keteladanan, pendekatan persuasif dengan menghargai nilai budaya, dan adat istiadat menjadi faktor penentu keberhasilan dakwah; bukan cara memaksa, menakut nakuti dan intimidasi yang tidak sesuai dengan semangat Islam sebagai agama damai. Dalam

\footnotetext{
16/bid.
} 
konteks Indonesia yang masyarakatnya plural, model pendekatan dakwah para da'i pendahulu yang telah berhasil menyebarkan Islam di Nusantara perlu tetap dipelihara dan dikembangkan, sehingga nilainilai Islam bisa tetap hidup dan menjiwai kehidupan masyarakat. 


\section{Daftar Pustaka}

Ali Aziz, Muhammad, Ilmu Dakwah (Jakarta: Kencana Prenada Media Group, 2009)

Brissett, Dennis dan Charles Edgley (ed.), Life as Theater (New York: Aldine de Gruyter, 1990)

Fisher, B. Aubrey, Teori-teori Komunikasi. teri. Soejono Trimo, (Bandung: Remaja Rosda Karya, 1986)

Hidayat, Komaruddin, "Agama Dan Postmodernisme," dalam Tragedi Raja Mida: Moralitas Agama dan Krisis Modernisme (Jakarta: Paramadina, 1998)

Jones, Philips, Theory and Method in Sociology: A Guide for The Beginner (Slough: Univercity Tutorial Press, 1985)

La Belle, Thomas \& Christopher Ward, Multiculturalism and Education (Albany: SUNY Press, 1994)

Mulyana, Deddy, Komunikasi Efektif, Suatu Pendekatan Lintas Budaya (Bandung: Remaja Rosdakarya, 2004)

Parekh, Bikhu, National Culture and Multiculturalism (New Delhi: Amar Prahasan, 1997)

Quinn Patton. Michael, Qualitative Evaluation and Research Methods. Second Edition (Newbury Park: Sage, 1990)

S. Ahmed, Akbar, "Postomdernism and Islam: Predicament and Promise", ter. M. Sirozi, Posmodernisme: Tantangan dan Harapan bagi Islam (Bandung: Mizan, 1993)

Suparlan, Parsudi, Menuju Masyarakat Indonesia yang Multikultural (Jakarta: Gramedia, 2002) 
Tasâmuh Volume 15, No. 1, Desember 2017

Suprapto, Tommy, Pengantar Teori Komunikasi (Yogjakarta: Media Presindo, 2006)

Tayler, Charles, Multiculturalism: Examining The Politics of Recognition. (Princeton: Princeton Univercity Press, 1994) 